\title{
A atualização da skholé e a escola contra a socialização
}

\author{
An update of skholé and school against socialization \\ La actualización de la skholé y la escuela contra la socialización
}

Cleriston Petry ${ }^{*}$

\section{Resumo}

Argumento, no presente artigo, sobre a relação entre socialização e educação, considerando a primeira como "processos de introdução na sociedade" e a segunda como a "introdução das novas gerações no mundo". O problema que orientou a investigação refere-se à existência ou não de incompatibilidade entre ambos os objetivos, se é razoável "socializar" considerando a "sociedade" em que crianças e jovens são inseridos e se a "socialização" contribui ou não para a realização da skholé, caracterizada como "tempo livre", distinto do "tempo produtivo" da sociedade. Nesse sentido, defendi que a skholé só é possível quando a "socialização" não é a tarefa central da escola (porque a "socialização" desescolariza a escola) e nem a educação reduzida à "socialização". A atualização da skholé e de sua institucionalização escolar é fundamental para a introdução das "novas gerações" no "mundo" e, talvez, a única oportunidade que os seres humanos terão, nas condições atuais, de experienciar o "tempo livre" que suspende as injunções da família, da sociedade (economia, trabalho, divertimento, lazer, descanso, aprendizagem) e da política.

Palavras-chave: educação; socialização; skholé.

\section{Abstract}

I argue, in this article, about the relationship between socialization and education, considering the first as "process of introduction into society" and the second as "the introduction of new generations into the world". The problem that guided the investigation refers to the existence or not of incompatibility between both objectives, whether it is reasonable to "socialize" considering the "society" in which children and young people are inserted and whether "socialization" contributes or not to the realization of skholé, characterized as "free time" distinct from society's "productive time". In this sense, I argued that skholé is only possible when "socialization" is not the central task of the school (because "socialization" unschools the school) or neither education reduced to "socialization". The updating of skhole and its school institutionalization is fundamental for the introduction of "new generations" into the "world" and, perhaps, the only opportunity that human beings will have, under the current conditions, to experience the "free time" that suspends injunctions of the family, society (economy, work, entertainment, leisure, rest, learning) and politics.

Keywords: education; socialization; skholé.

\author{
Recebido em: 29/07/2020 - Aprovado em: 06/01/2021 \\ http://dx.doi.org/10.5335/rep.v28i1.11458
}

Doutor em Educação pelo Programa de Pós-Graduação em Educação da Universidade de Passo Fundo (UPF). Professor do Departamento de Teoria e Fundamentos da Educação da Universidade Federal de Mato Grosso (UFMT) e do Mestrado Profissional em Filosofia (PROF-FILO), núcleo UFMT. Orcid: http://orcid.org/0000-0001-8900-6633. E-mail: cleripetry@hotmail.com 


\section{Resumen}

Discuto, en este artículo, la relación entre socialización y educación, considerando el primer como "procesos de introducción en la sociedad" y el segundo como "la introducción de nuevas generaciones en el mundo". El problema que ha conducido la investigación se refiere a la existencia o no de incompatibilidad entre ambos objetivos, si es razonable "socializar" considerando la "sociedad" en la que se insertan niños y jóvenes y si la "socialización" contribuye o no a la realización de skholé, caracterizada como "tiempo libre" distinto del "tiempo productivo" de la sociedad. En este sentido, sostuve que el skholé solo es posible cuando la "socialización" no es la tarea central de la escuela (porque la "socialización" no escolariza la escuela) o la educación se reduce a "socialización". La actualización del skholé y su institucionalización escolar es fundamental para la introducción de "nuevas generaciones" en el "mundo" y, tal vez, la única oportunidad que los seres humanos tendrán, en las condiciones actuales, para experimentar el "tiempo libre" que suspende los mandatos de la familia, la sociedad (economía, trabajo, entretenimiento, ocio, descanso, aprendizaje) y política.

Palabras-clave: educación; socialización; skholé.

\section{Introdução}

Só os homens sensatos e ESCLARECIDOS veem as coisas como são em si e trabalham para mantê-los em seu ser (RODRÍGUEZ, 2016, p. 99, grifos do autor).

A essência da educação é a natalidade, o fato de que seres nascem para o mundo (ARENDT, 2007, p. 223, grifos da autora).

Socialização e educação são termos que podem ser compreendidos como complementares, excludentes ou numa relação dialética. Para escrever sobre a socialização e a atualização da skholé, penso tais conceitos a partir, com e para além de Hannah Arendt. Mesmo que a autora não tenha se dedicado à elucidação do primeiro, seguirei pistas teóricas que me conduzirão, plausivelmente, às considerações que tecerei. Se pensarmos em socialização como "processos de introdução na sociedade", é preciso indagar: O que se entende por "introdução", isto é, como ela se realiza? Em qual sociedade os indivíduos serão introduzidos? Socialização é a finalidade da educação ou uma atividade complementar à educação e, por vezes, independente da educação?

Faço a opção por Arendt por desejar contribuir ao debate acerca da (não)relação entre "socialização" e educação. Para tanto, penso que considerar a "socialização" como "processos de introdução na sociedade" é uma definição geral que tipifica as diversas definições sociológicas do termo e do "fenômeno" para o qual todos passamos ou passaremos. As distinções conceituais feitas por Arendt, ademais, contribuem para esclarecer o sentido da escola, que advém de sua especificidade, especialmente quando a educação está em crise, a escola sob suspeita e a "educa- 
ção remota" como uma prática para enfrentar (ou não) o problema educacional em meio à pandemia. Não nascemos membros da sociedade, e a "socialização" exige "interiorização", a compreensão dos outros atores sociais, da realidade social e da vida que os outros já vivem, escrevem Peter L. Berger e Thomas Luckmann (2004, p. 174). Mas, o que ambos os sociólogos compreendem por sociedade é atribuível ora ao "mundo" ora à "vida", segundo a conceituação arendtiana. Por isso, e para manter a pretensa originalidade do presente artigo, pretendo tratar da relação entre "socialização", "educação" e skholé, tomando como ponto de partida um conceito amplo e geral de "socialização" e me localizando no espírito de pensamento de Hannah Arendt.

"Sociedade" é um conceito apropriado pela Sociologia, na Modernidade, para dar conta de sua especificidade e objeto de estudo, ou seja, aquilo que compõe a sociedade ou o que a sociedade é: um organismo vivo (em processo de evolução), a união de indivíduos a partir de um contrato, o conjunto das relações e ações sociais, uma realidade de situações partilhadas e nexo de motivações, etc. Evidentemente, o conceito de "sociedade" é anterior às Ciências Sociais, mas com estas houve uma abordagem científica do conceito/fenômeno. Com a Modernidade, a sociedade passou a significar o "auge da administração doméstica, suas atividades, problemas e planos organizativos" (ARENDT, 2005, p. 61) ${ }^{1}$. Essa caracterização, destoante da tradição sociológica, implica considerá-la como uma esfera em que os indivíduos, famílias e grupos se ocupam com as necessidades vitais, em que houve uma ressignificação para a vida individual e para a cidadania. Para compreender melhor a sociedade, enquanto conceito, é importante considerar que ela se opõe à política $\mathrm{e}$ ao privado, embora houve uma ressignificação do privado e do político com a emergência da sociedade. O que era privado, os interesses vitais, isto é, as necessidades relacionadas à sobrevivência, passou a ser público, e o que era público, os assuntos humanos, a política, deixou de ser relevante. A política, então, se converteu numa administração pública dos interesses privados, relativos ao acúmulo de capital, à defesa da "propriedade" privada e aos interesses individuais. O social passa a constituir a esfera pública e, por conseguinte, ocupar os interesses dos atores educacionais.

$\mathrm{O}$ advento da sociedade acarretou transformações também para a escola, que se desescolarizou. A sociedade, com a canalização pública do processo vital, a vitória do animal laborans e a publicização de suas atividades, acarretou na impossibilidade, lógica, da ação e do pensamento, donde a "socialização" significou adequação, conformação, nivelação, normalização e, no limite, solidão sob o império do 
comportamento. Na escola, o currículo também se altera com a transformação da "linguagem da educação" em "linguagem da aprendizagem", explicitada, no Brasil, pela adoção da Base Nacional Comum Curricular (BNCC).

A sociedade também é caracterizada pelo "tempo produtivo", tempo dedicado à "vida", ao metabolismo vital, à sobrevivência, aos negócios, à askholia. Nesse sentido, a relação entre "socialização" e "educação" só pode ser de oposição, quando pelo segundo se compreender que sua essência é a "natalidade", isto é, o fato de que seres nascem no "mundo", não na sociedade, não no trabalho, não na vida, não na família, e que a tarefa da escola é introduzir as "novas gerações" no "mundo" e não socializa-las. Para tanto, tal introdução demanda um tempo específico, a skholé, forma-ideia que inspira e pode constituir as escolas ante processos de desescolarização.

Neste artigo, ensaiei aproximações entre Arendt (1993, 2001, 2005, 2007, 2009, 2012), Rodríguez (2016) e Masschelein e Simons (2013), para repensar a atualização da skholé na América Latina como resposta às demandas da "sociedade" e às injunções da socialização. Fiz isso buscando a plausibilidade dos argumentos, abstendo-me da esperança de um "veredito final", ciente de que a última palavra não foi dada e que há outras possibilidades de se pensar a "socialização", embora nenhuma escape da "sociedade".

A investigação que resultou no presente artigo apresenta como "prova" a demonstração do relacionamento lógico entre os conceitos e argumentos: "o pesquisador qualitativo toma sobre seus ombros o fardo da plausibilidade" (SENNETT, 2014, p. 72). Sei que entre Arendt e Rodríguez há aspectos de convergência e de divergência, e que o conceito de "social" para o segundo tem um sentido de público/ político que não há em Arendt, autora que vislumbrou isso que denominou de "ascensão da sociedade". Mas o debate não é entre Arendt e Rodríguez, mas entre os argumentos e os que lerem o artigo. Meu compromisso não é defender autores, mas

pensar com, a partir, para além e contra eles, ou seja, pensar os pensamentos deles para pensar melhor os meus.

\section{A emergência da sociedade e a educação como socialização}

A “canalização pública do processo da vida” (ARENDT, 2005, p. 68) significa que as preocupações com as necessidades relacionadas à manutenção da vida estabelecem um domínio público próprio, numa forma de mútua dependência, e a transformação de todos os indivíduos em trabalhadores e do trabalho (labor) em 
uma atividade digna para aparecer em público. Na Modernidade, com o advento da sociedade, ou seja, com a absorção de todos os indivíduos na sociedade, houve a "vitória do animal laborans", do indivíduo (pré)ocupado exclusivamente com a "vida" e a perda de "mundo", isto é, de tudo o que é construído e constituído pelos homens por meio do discurso e da ação. Se nos resta laborar, o "mundo" está condenado à ruína do ciclo vital da natureza, da destruição. Nesse contexto,

[...] o único necessário foi trabalhar, com o fim de assegurar a continuidade da existência individual e de sua família. O não necessário, o não requerido pelo metabolismo da vida com a natureza, ou bem era supérfluo ou apenas podia justificar-se como peculiaridade do humano para diferenciá-lo de qualquer outra vida animal (ARENDT, 2005, p. 338).

Em meados de 1830, Honoré de Balzac (2013, p. 339) teceu críticas à sociedade francesa, na qual todos os segmentos sociais excediam sua existência para ganhar o ouro que os fascinava e/ou gozar de poderosos prazeres: "Sem as tabernas, o governo não seria derrubado todas as terças feiras?”. Com o advento da sociedade, tudo se torna "tempo produtivo": a sensação de "não ter tempo", de um tempo devorado, arrasado, consumido, destruído, dedicado aos negócios, a askholia. Outra indagação de Balzac (2013, p. 345) é reveladora: “onde coloca essa gente o coração?”. Com a Modernidade e a sociedade, chamamos "privado" uma esfera de intimidade, e o escritor francês percebe, no século XIX, o ataque e a desconsideração com o lugar no qual se é autêntico.

Anos antes, na mesma época, Rousseau se rebelou contra a sociedade e não contra o Estado (ARENDT, 2005, p. 62), e isso repercutiu em seu projeto educativo: é preciso formar o homem antes do cidadão (ROUSSEAU, 2017, p. 44); uma "educação natural" que principia pelos sentidos, na qual viver é o ofício a ensinar ao educando (ROUSSEAU, 2017, p. 46). A opção por uma educação doméstica visa proteger a criança da sociedade, dos vícios e costumes corrompidos, mas não das condições sob as quais ela poderia ter de viver. Ademais, a educação aconteceria no campo, pois "as cidades são o abismo da espécie humana" (ROUSSEAU, 2017, p. 67), um ambiente de corrupção em que se deseja o que não se pode ${ }^{2}$, se busca $o$ gozo acima de tudo, acarretando a infelicidade diante da realidade: vide o exemplo da riqueza como fim, um fim quimérico porque ela exige mais riqueza, num acúmulo ininterrupto, na "ilimitada apropriação" defendida por Locke em Dois tratados sobre o governo (2005).

É essa perpetuação do "metabolismo vital", o ciclo da vida e do capital, que é tornado público com o advento da sociedade na Modernidade, em detrimento do que é público (político) e privado. A alternativa de Balzac e Rousseau, a proteção da 
intimidade, não é suficiente para ocupar o espaço essencial da esfera privada, nem pode ser um substituto à esfera pública/política. Não é e não pode ser um substituto porque a intimidade e o que lhe é reservado não possui a realidade e a tangibilidade possível de uma esfera entre, especificamente a pública. Por outro lado, o ideal educativo de Rousseau, como também o de Locke (2019), não é um "antídoto razoável" à destruição do mundo e ao sentimento de solidão, próprio da sociedade, na medida em que se trata de um projeto individualista, típico da Modernidade. É possível que o educando de Locke e de Rousseau conclua a etapa formativa como um indivíduo virtuoso e disso não advém que será um cidadão, mas alguém equipado com um conjunto adequado de conhecimentos, habilidades e disposições, "sem formular perguntas sobre suas relações com os outros e sobre o contexto social e político em que aprendem e agem" (BIESTA, 2013, p. 158). Assim, uma crítica ao conceito de socialização deve ser, também, uma crítica à Modernidade, ao projeto educativo do Iluminismo e à concepção de tempo que lhe é própria.

A organização política da Sociedade é (foi) o Estado Nação e tem (e teve) a burocracia enquanto forma de governo. A burocracia é o governo de ninguém, a mais social forma de governo, escreve Arendt (2005). O "governo de ninguém" não é um não-governo, mas pode resultar numa de suas versões mais cruéis e tirânicas (ARENDT, 2005, p. 63). O governo do escritório, da administração, impessoalizado, atento às estatísticas, à frieza dos números e aos regulamentos, racional, portanto, governa uma sociedade de indivíduos atomizados e conformados. Para Arendt (2005, p. 63), há um conformismo inerente a toda sociedade e exigências tipicamente niveladoras do social, em que a sociedade "sempre exige que seus membros atuem como se fossem de uma enorme família com uma só opinião e interesse”. A sociedade exclui a possibilidade da ação e a substitui por comportamentos, que se distinguem da primeira pela previsibilidade, expectativa e conformação às normas sociais. Há a tendência à "normalização", isto é, ao enquadramento dos indivíduos e suas singularidades num "coletivo", inviabilizando e excluindo o surgimento do novo, do inédito, do inesperado, do revolucionário. Neste contexto, a educação como socialização se torna um agente conformador, nivelador, adaptador das crianças e jovens à sociedade, seu modelo de organização e experiência de tempo. A "igualização", fenômeno social, tornou a distinção e a diferença assuntos privados, relativos à intimidade e não à ação, isto é, a atuação na esfera pública por meio de palavras e ações.

Nesse sentido, o império do conformismo é a sociedade, espaço/tempo do surgimento da Sociologia, da Economia e da Estatística. Para Arendt, a Economia só 
pode adquirir um caráter científico quando os homens se constituem seres sociais, sob o critério judicativo da normalidade e da anormalidade. A estatística, como técnica de tratamento matemático da realidade, pressupõe que os acontecimentos são raros na vida das pessoas e todos são convertidos em números que demonstram tendências aptas a serem usadas por governos ou gestores ${ }^{3}$.

A Economia, ademais, foi cooptada pela "racionalidade neoliberal", uma racionalidade "totalitária" no sentido de que abrange todos os aspectos da vida e visa a formação de um sujeito adaptado a sua lógica (DARDOT; LAVAL, 2016). Além disso, os economistas neoclássicos não têm um apego aos fatos e pouco importa que as "soluções" e "estratégias" apresentadas deem errado em todos os lugares (ou não conquistem o que publicamente declaram ser a intenção). A economia neoclássica, escreve Joaquín Estefanía (2017, p. 83), "é responsável não apenas por não haver antecipado a Grande Recessão, mas por ser intrinsecamente errônea e nociva, ao haver contribuído a multiplicar as calamidades que intentava prever"4. No Brasil, a pandemia expôs a nu o fracasso do neoliberalismo, a humilhação pessoal da ideologia do indivíduo como empresário de si, ao mesmo tempo em que, num movimento contrário, a crueza da vida se tornou assunto público e expôs a luta pela sobrevivência, a fragilidade dos nossos corpos e a idiotice de nossa existência.

Se "o modo mais cômodo de conhecer uma cidade é averiguar como se trabalha nela, como se ama e como se morre" (CAMUS, 2003, p. 9), talvez tenhamos de concordar com o jovem Marx (2006), que, no ensaio Sobre o suicídio, escreve não se tratar de uma sociedade, mas de um deserto habitado por bestas selvagens, exceto que a sociedade não seja deserto, mas algo distinto.

A pandemia da Covid-19 evidencia a hipótese das ciências do comportamento, que "reduzem os homens, em todas as suas atividades, ao nível de um animal, de conduta condicionada" (ARENDT, 2005, p. 67). Entre A Peste e a Pandemia, fomos jogados no lar ou na humilhação do subemprego, do desemprego, da mortalidade como condição fundamental e não da natalidade. Em Camus (2003, p. 10), é a mortalidade que, ao aparecer como espetáculo pelas ruas de Orán, desnuda uma existência sem sentido, em que "nada é mais natural hoje em dia que ver as pessoas trabalhar de manhã à noite e em seguida escolher, entre o café, o jogo e a conversa, o modo de perder o tempo que nos resta por viver". Todos morremos, uma de nossas condições fundamentais, mas a peste tornou-a pública e, junto com ela, o absurdo de dedicar-se à vida, isto é, à manutenção da vida biológica, ao labor, trabalho, consumo, divertimento, descanso, num ciclo ininterrupto até a morte. Essa é uma das oportunidades da crise sanitária (por vezes, modo de governar): reconsiderar, 
repensar o que estamos fazendo. O "tempo livre" em Orán é um tempo matado, tempo de sobra entre o sono e o trabalho. Um tempo, portanto, não mais livre, mas ocupado, funcional ao labor, "tempo produtivo", tempo da sociedade.

O "tempo produtivo" é, também, cíclico, como o "metabolismo vital". Todos precisamos do labor, pois temos necessidades, somos seres vulneráveis, e essa condição de necessitados compartilhamos com outras formas de vida animal, o que não se considerava dignamente humano, na experiência greco-romana. "Ainda que estejam feitas pelo homem, vem e vão, são produzidas e consumidas, em consonância com o sempre repetido movimento cíclico da natureza" (ARENDT, 2005, p. 118). Deste modo, não são especificamente humanas. E dedicar-se toda a existência ao labor, consumo, descanso, lazer, sono e trabalho não era considerada uma forma de vida apta à excelência (areté), a deixar uma marca e converter a existência individual em algo mais permanente que a própria vida. Por outro lado, o tempo é "produtivo" quando o homem "fabrica", faz ou produz objetos visando sua utilidade ou quando o critério de julgamento para o "mundo" e a "vida" é a utilidade. Nesse aspecto, o tempo não é mais cíclico, mas a passagem de um passado-presente-futuro com a preponderância do futuro, donde a utilidade se realizará em seu próprio ciclo sem sentido. Deste modo, a mentalidade do fabricante moderno é a instrumentalidade e a utilidade, ambos que localizam os indivíduos num "tempo produtivo" porque o importante não é a atividade, o aqui, o isso, mas o produto final, o futuro e como ele será utilizado, vendido, tornado instrumento.

Trabalho (labor) e fabricação (work) são distintos, pois o primeiro é uma atividade que corresponde ao processo biológico do corpo humano e ao "metabolismo vital”, ligado às necessidades da vida. A fabricação, por outro lado, diz respeito ao não natural da existência do homem, à artificialidade do mundo de coisas (ARENDT, 2005). Com a fabricação, se constrói um mundo humano, mundo comum, mundo da arquitetura, das artes, da literatura, das ciências. Mas os instrumentos e as obras da fabricação não estão impedidos de serem usados para a produção de bens de consumo ou para atividades dedicadas ao tempo de lazer. A fabricação produz objetos culturais que podem durar e, por isso, constituir um mundo comum, testemunha do passado ao futuro, o que durará mais que a própria vida. Porém, com o último estágio de desenvolvimento da sociedade, a sociedade de massas, não se sente necessidade de cultura, mas de diversão "e os produtos oferecidos pela indústria de diversões são com efeito consumidos pela sociedade exatamente como quaisquer outros bens de consumo" (ARENDT, 2007, p. 257). Imersos num "tempo produtivo", de sempre estar atarefado, com negócios a resolver, o homem moderno 
não se dedica aos assuntos humanos nem ao pensamento. Balzac (2013, p. 346) argumenta que:

[...] obrigados a falar sem cessar, trocam todos o pensamento pela palavra, o sentimento pela frase, e suas almas transformam-se em laringe. Gastam-se e se desmoralizam. [...]. Deslizam sobre as coisas da vida e vivem cada instante impelidos pelos negócios da grande cidade.

É a sensação de não ter tempo, de estar sempre atrasado que atinge o ápice com a sociedade e a vitória do animal laborans, aquele que dedica toda sua existência a sobreviver e a alimentar o ciclo vital. A educação como socialização se converte num espaço/tempo de treinamento de aprendizes aptos a exercer uma função na sociedade. Do mesmo modo, a sociedade é considerada a partir de suas funções, e a estima dos indivíduos se deriva do lugar e do papel que exercem.

A escola e os indivíduos devem ter uma função, um lugar a ocupar na sociedade para definir suas identidades. Ao mesmo tempo, essa sociedade que exige funções que localizam o indivíduo em seu seio apenas lhe dá frágeis garantias de autoestima e consciência de si, porque os indivíduos não aparecem na modalidade do discurso e da ação, mas como trabalhadores, consumidores, acumuladores, acionistas, empreendedores. Numa crise sanitária, quando muitos são obrigados a ficar em casa, a trabalhar menos ou de outros modos, a crise se torna existencial: afinal, quem sou eu? Pergunta que não pode ser respondida na escuridão da vida privada, muito menos numa atividade de introspecção. Se na introspecção me deparo com o pensar, com o pensar sobre meus pensamentos; se o pensar é um diálogo silencioso comigo mesmo, ao pensar não sou só um, mas dois. Portanto, aquele que busca saber quem é pensando se deparará com a dualidade instaurada pelo pensar. “Até o próprio Sócrates, tão apaixonado pela praça pública, tem de voltar para casa, onde estará só, para encontrar o outro indivíduo" (ARENDT, 2009, p. 212). Diferentemente de Sócrates, a maioria dos brasileiros voltou para casa e se deparou com a sobrevivência, com os assuntos domésticos, com a privatividade do lar. Publicamente, por outro lado, restava o espetáculo da pandemia que envolveu tudo: "já não havia destinos individuais, mas uma história coletiva que era a peste e sentimentos compartilhados por todo mundo" (CAMUS, 2003, p. 149). Terreno fértil para governos autoritários. Diferente do "social" e da "sociedade" está a esfera privada. Privado significou estar desprovido de algo, das mais elevadas e humanas capacidades, argumenta Arendt (2005). Esse traço privativo do privado implicava estar privado de "coisas essenciais a uma verdadeira vida humana: estar privado da realidade que provém de ser visto e ouvido pelos demais e estar priva- 
do da <<objetiva>> relação com os outros" (ARENDT, 2005, p. 78), que acontece quando há um espaço-entre que une e separa os indivíduos, um mundo comum. A realidade se constitui pelos múltiplos pontos de vista nos quais os indivíduos ocupam o espaço com sua cultura, sua história, costumes, etc. Estar no mundo, na esfera pública, é ter a oportunidade de corrigir os sentidos pessoais com o "senso comum", o bom senso, no qual compartilhamos o mundo ao mesmo tempo em que ele se "objetiva" para nós.

A educação como socialização, ao adaptar os indivíduos à sociedade ou introduzi-los na sociedade não lhes garante a possibilidade de acessar o mundo comum e de se distinguir e atingir a excelência num espaço no qual compartilhamos o que é comum, nem de revisar nossos pontos de vista que podem ser equivocados, dado que "ponto de vista" não é a "verdade", e sozinho um indivíduo não constitui a realidade e, socialmente, é incapaz de levar uma vida excelente e singularizar-se. Na sociedade, ou na solidão da intimidade, carente de laços profundos com os outros, as teorias conspiratórias e alucinações fomentam a extrema-direita e saídas autoritárias para a carência de laços que unem os indivíduos. A alucinação é "uma distorção efetiva da capacidade de pensar fundada na necessidade de $s a$ turar a realidade com desejos que não suportam frustração, bem como no impacto corrosivo dos mecanismos psíquicos ligados ao ódio sobre o próprio pensamento" (AB'SABER, 2018, p. 129).

Socializado, talvez o homem seja incapaz de realizar algo mais permanente que a própria vida. Por isso, o homem privado e o homem socializado não aparecem, é como se não existissem (ARENDT, 2005, p. 78). O homem privado do mundo e do espaço público realiza coisas que carecem de significado e "consequência para os outros, o que lhe importa não importa aos demais" (ARENDT, 2005, p. 78). Daí que a solidão seja uma experiência cada vez mais comum na "sociedade" e, especialmente, na "sociedade de massas" de indivíduos atomizados, jogados em suas vidas privadas, ocupados com seus negócios e a sobrevivência, condição importante para a ascensão de movimentos fascistas e totalitários, afinal, quando se está só o coletivo se apresenta como um simulacro do calor familiar, em que o indivíduo importa porque faz parte, sabe o que é nessa vida sem sentido.

Por outro lado, Arendt (2005) apresenta traços não privativos do privado que os constitui como partes importantes se preservado o comum e o público, isto é, sem o privado, o comum careceria de sentido. Do mesmo modo, a necessidade é fundamental para a existência da liberdade. A eliminação da necessidade não acarreta a liberdade, como evidencia a busca pela riqueza e por poderosas diversões. $\mathrm{O}$ 
privado é o único lugar seguro e oculto do mundo. É nele onde as crianças podem se desenvolver sem a luz pública, sem os julgamentos da aparência, e para constituírem-se a si mesmas antes de enfrentar a esfera pública, dos acontecimentos e da publicidade. Para Arendt (2005, p. 86), "uma vida que transcorre em público, na presença dos outros, se faz superficial”. Na pandemia e, consequentemente, na crise sanitária, as pessoas sem um espaço privado de proteção estão condenadas a viver publicamente, a expor-se ao contágio, sem qualquer proteção. Estão sob os olhares de todos, mas são invisíveis, porque não importam, não são respeitadas ${ }^{5}$.

O espaço público, antes do advento da sociedade, era uma esfera de igualdade e de distinção, que se alcança ao agir em conjunto com outros seres humanos iguais e livres. Só no espaço público os homens podem mostrar quem são, e na esfera privada e social de suas vidas apenas são um que, isto é, exercem funções, atuam não como singulares, mas pertencentes a uma classe profissional, ao papel relativo à sobrevivência e à atenuação das necessidades. Nascemos únicos, mas nossa unicidade aparece na esfera pública que é o espaço da aparência, a qual constitui a realidade. Para Arendt (2005, p. 71), tudo o que aparece em público pode ser visto e ouvido e tem a mais ampla publicidade possível. Com o auge do social, o que se torna público são os interesses privados; e os indivíduos se tornam trabalhadores e/ou produtores. São os outros, numa esfera pública da ação e do discurso, que garantem a realidade do mundo e de nós mesmos. Sem a publicidade, é como se não existíssemos como singulares.

Público também significa o próprio mundo enquanto comum a todos e diferenciado do lugar que ocupamos privadamente nele. Se socialização significa os processos de introdução na sociedade, a educação como socialização acarreta numa perda de mundo e da aparência necessária para que cada um apareça como único, com sua dignidade própria.

Num contexto socializado, a pandemia conta seus mortos estatisticamente e, por conseguinte, é carente de realidade quem morre. Sabemos apenas o que morre: corpos, espécimes humanos. É muito mais fácil matar (e deixar morrer!) quando não há indivíduos singulares, mas números ${ }^{6}$. Um amontoado anônimo. Escreve Camus (2003, p. 39): "mas, o que são cem milhões de mortos? Quando se fez a guerra ninguém sabe o que é um morto. $\mathrm{E}$ ademais, um homem morto apenas tem peso quando se viu um morto; cem milhões de cadáveres jogados através da história, não são mais que fumaça na imaginação".

Com a pandemia e as aulas on-line, as crianças tiveram de ficar em casa e foram privadas do acesso ao mundo ou, simplesmente, à sociedade. Evidentemente 
que o acessam pela internet, mas essa ferramenta não é um espaço-entre, trata-se de uma tecnologia que media a relação dos seres humanos entre si e com o mundo. As redes sociais, especificamente, não são espaços públicos, e os indivíduos que lá "aparecem" controlam as personas bem como o ambiente de interação (como o ambiente é controlado pelos interesses comerciais dos donos das plataformas). Portanto, a internet não é pública porque é dominada por empresas privadas que utilizam nossos dados para lucrar e criar algoritmos, gerar tendências, comportamentos e turbinar vendas; não é espaço público porque o mundo virtual não é o mundo real. Ter fotos do Mont-Saint-Michel não me torna proprietário, muito menos me confere a possibilidade de realizar uma experiência estética profunda semelhante ao estrangeiro que o visita, nem o espaço se torna comum. A internet nos deu um simulacro do "público", e as redes sociais são somente sociais: a publicização de interesses privados e personagens que não se revelam, é o aparecer (quando não a mentira) do que são. Os alunos, presos em casa para sobreviver, são privados da escola e do que é específico da skholé, pois em casa se comportam conforme funções, têm o passado e o futuro de expectativas nas costas e estão numa esfera com sua linguagem e lógica própria.

Quando a socialização é mais importante que a educação, a escola é domada pela sociedade, pelas expectativas sociais, pelas demandas do trabalho, do consumo, do lazer e da economia, isto é, a escola passa a ser uma função da "vida", da sobrevivência da espécie e da manutenção do ciclo vital. "Domar a escola implica governar seu caráter democrático, público e renovador. Isso envolve a reapropriação e reprivatização do tempo público, do espaço público e do 'bem comum' possibilitados por ela" (MASSCHELEIN; SIMONS, 2013, p. 106). Não por acaso, Bolsonaro vem atacando a educação pública desde que assumiu o poder, nomeando ministros que degradam as instituições públicas, reiteram o corte dos investimentos e aniquilam a educação nos termos apresentados.

A escola, sob a égide da socialização, é vista como um meio para resolver problemas sociais, e numa sociedade de trabalhadores sua função é a de criar condições para formar o empreendedor, o indivíduo empresário de si mesmo, e o faz, entre outros meios, utilizando a "linguagem da aprendizagem". Para Gert Biesta (2013), a linguagem constitui a realidade e as relações que os indivíduos estabelecem entre si e com o mundo. Há, nos últimos anos, a alteração de uma "linguagem da educação" para uma "linguagem da aprendizagem", em que ensinar "foi redefinido como apoiar ou facilitar a aprendizagem, assim como a educação é frequentemente descrita como propiciadora de oportunidades ou experiências de aprendizagem" 
(BIESTA, 2013, p. 32). No Brasil, a linguagem da aprendizagem, do "aprender a aprender", é a lógica que estrutura a BNCC, discutida no governo Dilma e aprovada no governo Temer. É interessante que esse documento, que unifica a base de conhecimentos para todo o território do Estado brasileiro, não utilize nenhuma vez a palavra "educação": tudo se transforma em aprendizagem. Outro dado importante é que "democracia" também é omitido. Ademais, há a lógica do desempenho, da performance e não mais do acesso ao mundo, às verdades.

A BNCC possui uma concepção reduzida de conteúdo: habilidades e competências visam garantir a permanência e a aprendizagem dos estudantes respondendo às suas aspirações (BRASIL, 2018, p. 461). A "linguagem da aprendizagem", conforme Biesta (2013), é muito mais individualista, embora esteja dentro da ideia de "socialização" como "processos de introdução na sociedade". Neste viés, a sociedade em que os jovens serão inseridos é uma sociedade do "tempo produtivo", da solidão e, mais recentemente, da "racionalidade neoliberal" que tende a ocupar todos os espaços da existência (público, privado, política, economia, lazer, educação, consumo, esportes), mas não o "tempo livre", porque é capaz de destruí-lo, não colonizá-lo. $\mathrm{O}$ afastamento da BNCC do "mundo" é explicitado quando o documento disserta sobre as aprendizagens necessárias:

[...] em lugar de pretender que os jovens apenas aprendam o que já sabemos, o mundo deve lhes ser apresentado como campo aberto para a investigação e intervenção quanto a seus aspectos sociais, produtivos, ambientais e culturais (BRASIL, 2018, p. 463).

A “apresentação" do "mundo" é uma boa intenção que se anula pelo modo como ele é apresentado: algo a ser aprendido por meio de habilidades e competências adquiridas no percurso escolar. A primeira consequência dessa "educação como socialização" é o abandono das crianças e jovens aos seus próprios recursos e a substituição do aprendizado (educacional) pelo fazer (habilidades e competências). Arendt (2007, p. 232) argumenta que reformas semelhantes nos Estados Unidos tiveram a intenção não de ensinar conhecimentos, mas de inculcar habilidades, transformando as instituições escolares em instituições vocacionais, tornando-se incapazes de fazer com que a criança adquirisse os pré-requisitos normais de um currículo padrão. Em segundo lugar, essa educação marca o encontro da economia com a escola, a confusão da linguagem econômica e educativa que transforma as "políticas educativas" em políticas de adaptação ao mundo do trabalho, acarretando a perda de autonomia da escola e a estigmatização da educação pública (LAVAL, 2004, p. 66). 
A defesa da escola, numa sociedade do trabalho e do desemprego, se fundamenta numa reforma educacional que visa oferecer uma mão de obra adaptada e concebe os alunos não mais que futuros trabalhadores, responsáveis por si mesmos, pela sua aprendizagem e pelo constante reinvestimento de suas capacidades e habilidades. O que acontece com a escola quando a socialização é o critério valorativo e o princípio avaliativo é que há um "processo de aclimatação a valores e comportamentos esperados de todos os 'colaboradores' da empresa" (LAVAL, 2004, p. 79). A "educação como socialização" não desconecta os jovens do tempo ocupado da família, da economia, do trabalho, em suma, da sociedade, da "vida". Nesse sentido, contra a socialização, é preciso pensar a educação e a possibilidade do "tempo livre" como alternativas ao modelo escolar desescolarizado.

\section{A desaparição da skholé e a revitalização dos muros da escola}

Entendo que para pensar a escola e as atividades que a compõem é preciso considerar e refletir sobre a origem da palavra e da experiência dela derivada, skholé. Segundo Kostas Kalimtzis (2017), skholé foi um conceito fundamental para a Filosofia Ocidental, especialmente em Platão e Aristóteles, para os quais significava tempo livre para homens livres, isto é, o tempo do filosofar. Arendt (2005, p. 40) compreende a skholé antecipada pela liberdade da necessidade e da coação dos demais, além de um cesse de atividade política e liberdade de preocupações e cuidados. Nesse sentido, a skholé pode ser o espaço/tempo de atividades que não estejam ligadas às necessidades da "vida", à utilidade da produção e à política, aos assuntos daqueles que também estão liberados das necessidades e vivem um tempo especial de liberdade e igualdade com outros cidadãos.

Kalimtzis (2017), por outro lado, argumenta que no período Bizantino o conceito se metamorfoseou, passou por um processo de perda da valoração positiva e, por conseguinte, desapareceu do grego moderno, embora o verbete skholé, apresentado pelo autor, deixa claro a sua transformação no sentido de "institucionalização", isto é, no grego moderno, skholé passa a significar as instituições de aprendizagem e pesquisa. No caso brasileiro, a escola é a instituição que compreende toda a formação básica dos cidadãos. A "institucionalização" da skholé exige uma diferenciação entre a escola "real", a que se realiza na prática dos atores, e a forma/ideia, que mobiliza o pensamento e estabelece parâmetros para o que poderia ser o escolar. Como educadores e pesquisadores, “devemos questionar se essa escola que encontramos é 
realmente uma escola, se o que encontramos na instituição escolar responde ao que é uma escola" (KOHAN, 2015, p. 132).

Apesar da metamorfose da skholé, há elementos nas tradições subsequentes que podem inspirar uma atualização e ressignificação do conceito para constituirmos uma nova experiência. Em Filón (apud KALIMTZIS, 2017, p. 5-6), filósofo greco-judaico, skholé é uma atividade apropriada ao sabath; atividade moral dedicada a Deus, "retirada da turbulência dos assuntos públicos e terrenos"; um modo de habitar, por meio da contemplação (theôrein); dedicar-se à Filosofia, no sentido da avaliação e melhora moral. Dessas definições, skholé é uma atividade moral, religiosa, um retirar-se dos negócios da askholia para contemplar - embora a contemplação não seja uma atividade, tal como a compreendemos segundo Arendt (2005). O que se destaca é a "retirada" temporária, a saída dos negócios, daquilo que ocupa o tempo corrente e as relações habituais. Uma parada e, no sentido moral, um "pare e pense".

Para os Padres da Igreja, especialmente São Basílio, skholé significa quietude, a recomendação, obviamente centrada na vita contemplativa, de deter o que se está fazendo, deixar de fazer o que está ocupando-o, parar de se ocupar com o que é aparente, e a retirada moral em Deus (KALIMTZIS, 2017, p. 9). Novamente, a ideia de deter o ordinário, o corriqueiro, os negócios e ocupações relativas à sobrevivência, à riqueza, ao não fundamental para uma vida digna compõe a experiência da skholé. Com Gregório de Nisa, sempre a partir dos estudos de Kalimtzis (2017, p. 12-14), a skholé desaparece com seu conteúdo normativo que, de algum modo, derivava das experiências gregas e dá lugar à plegaria, especialmente no Oriente Bizantino. Tal conceito implica a atividade da oração na qual nos mantemos em comunidade com Deus, um dever para os cristãos. A askholia passou a significar os assuntos humanos, daqueles que se esquecem de Deus, que se ocupam com o corpo. Se há escola, nesses termos, ela tem de servir ao ideal da plegaria, não da skholé que ganha um sentido ambíguo e negativo.

O desaparecimento da significação originária de skholé conduziu a transformações de seu significado e a institucionalização do conceito, ou seu formalismo, isto é, mera forma conceitual para abarcar uma série de processos relacionados à educação e à formação das "novas gerações" entre muros. A escola Moderna, após revoluções democráticas, massificou o acesso à educação escolar, ao mesmo tempo em que conformou os indivíduos ao seu estatuto, especialmente o de compreender "o tempo como progresso, ou seja, a superação do passado [...] O mecanismo da superação implica uma relação necessária entre novidade e negação” (LÓPEZ, 
2014, p. 84). A Modernidade é autoconsciente de sua condição de ruptura com a tradição e a contemporaneidade. Os eventos e acontecimentos, a partir do século $\mathrm{XX}$, radicalizaram essa ruptura: rompe-se com o passado, que é considerado sinal de atraso. A busca constante por novos conhecimentos e capacitações, consequência da ressignificação do passado, repercute na formação e na educação.

Trata-se, segundo Sennett (2006, p. 47), da formação de uma "individualidade idealizada: um indivíduo constantemente adquirindo novas capacitações, alterando sua "base de conhecimento"'. A BNCC repercute essa tendência numa crítica ideológica ao "excesso de componentes curriculares", à exigência de as aprendizagens responderem aspirações individuais presentes e futuras (2018, p. 461), às "rápidas transformações decorrentes do desenvolvimento tecnológico" num contexto "cada vez mais complexo, dinâmico, fluido" e de incertezas (2018, p. 462) que exigem dos estudantes a abertura criativa ao novo. Neste contexto, os conteúdos, isto é, o passado, deixa de ser fonte de inspiração e guia. O "novo" é a negação do passado e a afirmação de algo distinto, o tempo como progresso.

A simples transposição da skholé grega à escola moderna só é possível com a suspensão do ideário inerente a ambas. A escola moderna incorpora o "outro" como uma de suas funções civilizatórias e a skholé grega excluiu o outro, o bárbaro, o estrangeiro, que, quando incorporado, o é no sistema relegado aos serviços, não ao tempo livre ou a política, lugar dos excelentes. A escola moderna está relacionada ao processo civilizatório e de "humanização" que "só é possível por meio da invenção de uma in-humanidade alheia, que dá à máquina 'antropológica' seu caráter dinâmico e produtivo" (LÓPEZ, 2014, p. 89, grifos do autor). Assim, a atualização da skholé tem de lidar com um duplo desafio: a exclusão grega e a assimilação moderna. Para tanto, a skholé precisa ser um tempo de suspensão.

Em primeiro lugar, a skholé é o tempo de suspender os modos habituais de nos relacionarmos com o tempo, com a linguagem e com os outros. Assim, na escola escolar se suspende a noção e a ideologia do progresso que assimila os "estranhos" ao mesmo tempo em que a ruptura com a tradição desemboca numa "linguagem da aprendizagem". "Humanizar" se converte num "socializar", conforme argumentei no tópico anterior. $\mathrm{O}$ outro, agora, aparece em sua radicalidade porque a suspensão do "progresso", e da lógica colonial inerente, implica a acolhida do outro como singular e a ideia de que um "nós" não antecede nem é proeminente ao quem de cada indivíduo que aparece por meio do discurso e da ação. Sendo assim, não há um quem antes da ação e nem isoladamente. Precisamos dos outros para termos realidade e os outros de nós. 
A suspensão, portanto, implica que "a escola dá às pessoas a chance (temporariamente, por um curto espaço de tempo) de deixar o seu passado e os antecedentes familiares para trás e se tornarem um aluno como qualquer outro" (MASSCHELEIN; SIMONS, 2013, p. 31). Tornar-se "aluno" não quer dizer ser anulado em sua singularidade, mas significa que é possível iniciar, começar outra vez, inserir-se no mundo como um novo ser humano e reconhecer-se como novo em relação a si mesmo e aos demais. Para atingir esse objetivo, a escola precisa suspender os requisitos, as funções, as expectativas sociais, econômicas, políticas e familiares. "A suspensão, tal como entendemos aqui, significa (temporariamente) tornar algo inoperante, ou, em outras palavras, tirá-lo da produção, liberando-o, retirando-o de seu contexto normal" (MASSCHELEIN; SIMONS, 2013, p. 32-33).

Essa suspensão é uma espécie de "perdão" que a skholé fornece como possibilidade àqueles machucados, marcados pelos papéis, funções, julgamentos e expectativas sociais, familiares, econômicas e políticas. Mas o perdão, embora dirigido aos "novos", não pressupõe culpa ou responsabilidade. No fundo, se perdoa porque sem o perdão não há como começar outra vez; se perdoa porque os adultos são os representantes do mundo e responsáveis pelo desenvolvimento das crianças e sua introdução na existência adulta. Infelizmente, poucos estão dispostos, sabem ou se interessam por isso. Daí, a skholé se instaura como um pedido de perdão para que o novo possa surgir e os atores continuem suas histórias. Portanto, o perdão também é uma suspensão.

Sem ser perdoados, liberados das consequências do que fizemos, nossa capacidade para atuar ficaria, por dizer assim, confinada a um só ato do qual nunca poderíamos recobrar-nos; seríamos para sempre vítimas de suas consequências, semelhantes ao aprendiz de bruxo que carecia da fórmula mágica para romper o feitiço (ARENDT, 2005, p. 256-257).

Evidentemente que o "perdão" que advogo não é no sentido do penitente e/ou culpado/responsável, mas daqueles que não podem ser responsabilizados porque estão em processo de formação e educação. Cada professor instaura a skholé em sua aula. Não há skholé a priori na escola. Ela precisa ser escolarizada. O perdão, como suspensão, permite que a aula comece. As dores, frustrações, juízos e avaliações são suspensas, colocadas de lado, os alunos são separados do contexto. A suspensão que rompe com "a solidão e a vergonha do aluno que não compreende, perdido num mundo em que todos os demais compreendem" (PENNAC, 2008, p. 34); a suspensão dos juízos sobre a valia de si e as previsões acerca do futuro, "crianças que não chegarão a nada" (PENNAC, 2008, p. 49); e a possibilidade de começar outra vez, prática do perdão: 
[...] o que entra na sala de aula é uma cebola: umas capas de pesadelo, de medo, de inquietude, de rancor, de cólera, de desejos insatisfeitos, de furiosas renúncias acumuladas sobre um fundo de vergonhoso passado, de presente ameaçador, de futuro condenado. Olhe-os, aqui chegam, com o corpo a meio fazer e sua família na mochila. Na realidade, a aula só começa quando deixam o fardo no chão e a cebola foi descascada. É difícil explicar, mas frequentemente só basta um olhar, uma palavra amável, uma frase de adulto confiado, claro e estável, para dissolver esses pesares, aliviar os espíritos, instalá-los no presente (PENNAC, 2008, p. 58).

O perdão é um autoperdão daqueles que não têm culpa E, orientados pelo professor, o adulto, podem começar outra vez, aqui, agora, nisso. A skholé, que suspende a sociedade e os mecanismos da socialização, acontece no "tempo presente", liberando os alunos da carga do passado e das injunções do futuro. Aqui podem começar outra vez, dedicados nisso, independente do que foram ou do que a sociedade, a família, o trabalho, a economia ou a política espera. Um tempo especial de aprendizagem (PENNAC, 2008, p. 59), desvinculado do papel social, das funções. Tempo do respeito, isto é, tempo em que todos são considerados como importantes, são vistos e ouvidos, aparecem e respondem ao mundo. Não são pacientes da educação, mas atuantes. E a atuação não é apropriação, mas resposta. "Enquanto a aprendizagem como aquisição consiste em obter mais e mais, a aprendizagem como resposta consiste em mostrar quem você é e em que posição está”, argumenta Biesta (2013, p. 47). Evidencia-se a diferença da escolarização como skholé da escolarização como socialização possibilitada, em nosso contexto, por uma "linguagem da aprendizagem".

A atualização da skholé também implica a suspensão das hierarquias e desigualdades sociais: "ela se dirige a todos por igual; nela o mundo pode ser renovado pelas novas gerações”, argumenta Kohan (2017, p. 593). De algum modo, havia comentado sobre essa especificidade quando escrevi sobre a suspensão das tentativas de domar a escola pela sociedade e pela família (e, hoje, a economia e a política criam hierarquias sociais tão verticais quanto as do Ancien Régime). Essa suspensão rompe com o discurso (e a prática) de que a escola reproduz as desigualdades sociais. A escola escolar, a escola fundada na skholé, é a instituição mais apropriada para romper com a desigualdade social de fato, e não apenas de direito. Ao localizar as crianças, adolescentes e jovens no "tempo presente", a escola os liberta do peso das dinâmicas sociais sob o princípio e o fato da igualdade, isto é, do "todos são capazes de". A igualdade, na Modernidade, "necessita estar prometida, mas jamais realizada, pois o dispositivo extrai sua força do desejo de igualdade, e não da igualdade efetiva" (LÓPES, 2014, p. 90). Por isso, a skholé é revolucionária e 
perigosa, é a materialização de uma crença utópica (KOHAN, 2017, p. 592), e a escola pública, espaço privilegiado para a skholé. A escola, segundo sua forma-ideia, é um espaço em que é possível "perder tempo", "perder-se no tempo", distinto dos espaços externos em que as pessoas são funções, exercem papéis e não têm tempo a perder, pois estão dedicadas aos negócios, à produção, ao consumo, ao trabalho, à askholia. O tempo da skholé é tempo de estudo, de dedicação a si mesmo, de cultivar-se (KOHAN, 2015, p. 134).

É inevitável, portanto, mencionar a experiência de Simón Rodriguez, educador e filósofo latino-americano que empreendeu uma educação popular no continente para contribuir com a formação de uma nascente República. Rodríguez sabia que a ruptura com o passado colonial e monárquico da Espanha se fazia, também, com a formação, e a escola poderia ser o princípio de um projeto para uma nova América - sem, com isso, entender que a educação deva assumir a responsabilidade utópica. Para Durán e Kohan (2016, p. 17),

[...] a igualdade na escola é declarada como princípio, e não como um objetivo a ser alcançado. Em seu interior, a igualdade se afirma e é praticada sem condições. A afirmação de uma realidade igualitária cancela, dentro da escola, a desigualdade que impera na cidade.

Por isso, a educação não pode se resumir a socialização, a introduzir os jovens na sociedade. Como introduzi-los numa sociedade desigual, fundada na lógica da sobrevivência, da publicização do labor, da existência encaixada inteiramente no "tempo produtivo"? Tal educação não é educação, mas uma condenação sumária das crianças e jovens, na medida em que não permite que elas apareçam como seres singulares. Neste sentido, igualdade não é “igualização", pois a igualdade, como princípio e ponto de partida, permite a todos aparecerem como singulares, e não a anulação das singularidades por uma "igualdade" que reduz as crianças e jovens a exemplares de uma espécie. Argumentam Masschelein e Simons (2013, p. 71) que "a escola e o professor que visam manter as mentes dos alunos no início da aula partem do pressuposto de que todos têm igual capacidade”, o que não significa acessar o mundo do mesmo modo nem responder às demandas, questões e insinuações do mundo e dos outros igualmente. $\mathrm{O}$ professor e a escola introduzem as "novas gerações" no mundo, o tornam público, colocando "todos numa posição inicial igual e fornece a todos a oportunidade de começar" (MASSCHELEIN; SIMONS, 2013, p. 71), ou seja, de agir. Na educação como socialização não há ação, mas comportamento. A igualdade, se houver, é um fim, não o princípio da ação pedagógica. Ir à escola não é natural às crianças. Trata-se de uma convenção, uma criação humana para garantir a continuidade do mundo e a formação. Como ar- 
gumentei anteriormente, a escola é um fenômeno do mundo, não da vida, no qual a skholé garante a especificidade de uma instituição sob ataque e tentativas de domínio. E a escola precisa da "suspensão" porque, como a escola de Rodríguez, a skholé também inverte ou cancela os valores da sociedade, suspende a ordem social e oferece uma nova prática pedagógica e um novo modo de existir. Por isso, a escola precisa de seus muros, muros de concreto e muros simbólicos: "a separação do mundo é a condição de possibilidade do escolar” (KOHAN, 2017, p. 593).

A igualdade na escola, princípio e prática, assume seu aspecto público: se todos são capazes, todos têm acesso ao que é (ou deve ser) público, o comum. Em Rodríguez, o Estado tem interesse na formação de todos os cidadãos porque não é possível excluir alguém se todos os ofícios e atividades implicam conhecimento. Mesmo para a "vida", tal ideia é fundamental, pois "que progresso farão os homens sem instrução?" (RODRÍGUEZ, 2016, p. 40). Por outro lado, uma educação republicana é fundamental numa República, donde uma instrução técnica (ou para a técnica) é incompleta. A escola republicana, sob o axioma da igualdade, conta com um adulto competente, versado na sua "matéria", apto a oportunizar a todos a experiência de "ser capaz de". Na escola escolar, ou seja, na skholé não é qualquer professor, material, livro, avaliação, estrutura ou relação que serve. O desafio, em nosso continente, não é socializar, nem imitar ou adaptar as diretrizes dos organismos internacionais para produzir trabalhadores mais competitivos. Contudo, entre Arendt e Rodríguez há uma controvérsia. Para o venezuelano, segundo Kohan (2015, p. 89), a verdadeira educação acontece entre iguais, pois entre desiguais há antipatia, submissão. O professor, então, deve considerar os estudantes como iguais. Sem dúvida, são iguais enquanto "seres capazes de", ambos são estudantes (KOHAN, 2015, p. 87) e um se inspira no outro e o mobiliza para o desejo de saber. Contudo, para Arendt, a autoridade do professor, que implica desigualdade e hierarquia, é constitutiva da relação pedagógica, entre adultos e crianças, pois os professores são os representantes do "mundo" frente às crianças, e são responsáveis pelo "mundo" e pelo desenvolvimento das crianças. Sem as especificações da igualdade entre professor e alunos que apresentei acima, igualdade formal, a igualdade de fato entre professores e alunos rompe com relações tipicamente geracionais e acarreta o "banimento" das crianças do mundo e uma desresponsabilização do adulto. Portanto, às afirmações de Rodriguez, é fundamental acrescer as condições de Arendt, que complementam e preservam as distinções que cuidam, conduzem e introduzem as crianças no mundo, essência da escola (ARENDT, 2007). 
A skholé latino-americana deve ser inventada, a partir de experimentos e experiências de educadores em suas aulas, onde acontece a ação, em que os seres humanos aparecem como singulares. Para Rodríguez (2017, p. 54-55, grifos do autor),

[...] a América está chamada (se os que a governam entendem) a ser modelo de boa sociedade, sem mais trabalho a adaptar. Tudo está feito (na Europa especialmente). Peguem o que é bom - deixem o que é mau - imitem com juízo - e o que lhes faltar INVENTEM.

Para inventar uma skholé latino-americana, é preciso esquecer o que entendemos por escola "para passar a considerá-la a partir de sua etimologia grega, skholé, como uma forma particular de tempo, um 'tempo livre' sem destino, sem objetivo ou fim" (OLARIETA, 2014, p. 51). Do mesmo modo, a experiência grega e as metamorfoses do conceito não nos servem, não atendem as exigências de nosso contexto. É preciso atualizar a skholé conforme venho argumentando, salvando o mundo das ruínas da laborização da existência e, num contexto em que tudo é passível de apropriação, profanar o sagrado, isto é, o que era privado de acesso público (AGAMBEN, 2007), liberar para o "livre uso", sem as injunções das funcionalidades previstas socialmente, laboralmente, economicamente, tecnicamente, profissionalmente. Tal "profanação" quer dizer uma ressignificação que ocorre quando algo é desligado de seu uso habitual e fica acessível para todos (MASSCHELEIN; SIMONS, 2013, p. 39). As crianças e jovens, ao profanar, mediados e orientados pelo professor - o representante do mundo -, têm a possibilidade de experimentar a si mesmas como "nova geração", e ao mundo como algo distinto de si mesmo, que confronta, desafia e exige respostas.

Mas uma skholé latino-americana não quer dizer que deva ser uma escola fundada em experiências indígenas ou negras, mas uma escola para todos e todas, uma escola para os despossuídos de terra, de cultura, de linguagem, de pensamento, de vida, de mundo (KOHAN, 2015, p. 55). É importante que cada um possa ser o que é e aparecer como quem é, ou seja, que sejam índios, negros, com suas línguas e culturas valorizadas e tornadas "comum", ao mesmo tempo em que a cultura europeia, estadunidense, asiática e que constituem nossa herança tenham espaço e tempo. Não se trata de pensar uma skholé americanizada, mas para a América Latina. O que Rodríguez quer para a América quer para todos, "e a inventiva que pede para a América se justifica porque o que ela necessita não existe noutro lugar" (KOHAN, 2015, p. 76).

Nesse sentido, a skholé é o tempo da "experiência" que só é possível no tempo presente e no tempo livre. Na educação em que é preciso estudar para fazer provas, preparar-se ao vestibular, formar-se para o trabalho ou para a localização na 
sociedade, não há tempo para realizar experiências com o mundo e com os outros. O "mundo", liberado de seus "usos", aparece na escola como "matérias", por isso a escola "profana". Um livro de Camus sai das mãos científicas de um pesquisador universitário dos departamentos de Filosofia e Literatura e passa a ser manuseado livremente pelos alunos, orientados pelos professores a realizar experiências com o texto, confrontados com a leitura e, assim, consigo mesmos. "Ler um texto", escreve Larrosa (2017, p. 128) "é, fundamentalmente, escutar a interpelação que nos dirige e fazer-se responsável por ela". Portanto, cabe ao professor fazer boas perguntas, mobilizar os alunos ao texto, introduzi-los no texto e, assim, numa parte do mundo. Ao mesmo tempo, cabe ouvi-los, pô-los em relação, na construção do "senso comum".

"Senso comum" e "mundo" estão articulados. A tarefa da educação, já anunciada, é a de introduzir as "novas gerações" no "mundo", realizando a transição do domínio familiar à esfera pública, espaço do comum. "O fundamento do Sistema Republicano está na opinião do povo, e esta não se forma sem instruí-lo", escreve Simón Rodríguez (2016, p. 55). A escola republicana desprivatiza os conhecimentos, torna-os públicos, de acesso geral. Por isso, defender a escola pública e gratuita é condição necessária para a existência da República e da continuidade do mundo. Rodríguez (2016, p. 117) defende que "os conhecimentos são PROPRIEDADE PÚBLICA", donde num regime de apropriação de tudo por todos, que é o capitalismo neoliberal, a escola exerce uma tarefa fundamental em relação à defesa do "mundo" e do "comum". Do mesmo modo, a República se fundamenta na opinião dos cidadãos, e isso não significa um "império da opinião", da absolutização da "liberdade de opinião". "A liberdade de opinião é uma farsa, a não ser que a informação fatual seja garantida e que os próprios fatos não sejam questionados" (ARENDT, 2007, p. 295). Por isso, a educação exige o ensino que se volta ao passado, e todo conhecimento se refere ao que passou. Por isso, a BNCC e a "linguagem da aprendizagem" põem em risco o "mundo" e a existência do sistema republicano. "O homem não é verdadeiramente desprezível senão por sua ignorância” (RODRÍGUEZ, 2016, p. 53). Do mesmo modo, é a partir dos eventos e acontecimentos que mobilizamos o pensamento. Mas, para pensar, é preciso sair temporariamente do "mundo", da "sociedade", dos afazeres cotidianos.

É na escola que dedicamos a atenção ao "mundo", convertido em "matéria. Estar atento quer dizer dedicar-se a isso, aqui e agora durante um período. Essa dedicação, na escola, é o estudo que exige o conhecimento e o pensamento. O conhecimento possibilita a inserção no "mundo", no que é essencial para saber localizar-se nele. O pensamento, por seu turno, busca o significado daquilo que acontece, 
rompe com clichês, frases feitas, estereótipos, pré-juízos e pré-conceitos que têm a função de nos proteger da realidade, de evitar a realização de experiências. E se, para pensar, é preciso sair temporariamente do "mundo", e a escola não é o mundo (ARENDT, 2007), é também a escola, quando fundada na skholé, um espaço/tempo do pensar que interrompe toda a ação, todas as atividades habituais (ARENDT, 1993, p. 149). Nesse contexto, a escola desnaturaliza o que a socialização tende a naturalizar na forma de comportamentos. Se o pensamento interrompe o cotidiano, a skholé estabelece uma ruptura temporal e espacial: tempo e espaço para pensar.

E nesse aspecto, a atualização da skholé para a escola recupera sentidos perdidos da skholé na Antiguidade para atualizá-los na formação e educação de crianças e jovens. Na educação como socialização não há espaço e tempo para o pensar, porque "o pensar representa perigo igual para todos os credos, e não dá origem, por si mesmo, a nenhum novo credo" (ARENDT, 1993, p. 159).

A socialização, como processos de introdução na sociedade, se fundamenta em intencionalidades (dos agentes concernidos), mas não em reflexão, em "pare e pense", em "suspensão": isso inviabilizaria o processo de socialização. Por outro lado, isso não significa que a socialização seja autoritária, totalitária. Seu problema é introduzir na sociedade e não no "mundo". A escola pode dedicar-se a ambos, desde que não esqueça que a maior parte do tempo e de seu espaço deve ser de skholé, do "tempo livre", não do "tempo produtivo". Porém, se a escola suspende o "tempo produtivo" e o tempo da sociedade é "produtivo”, então não há condições, lógicas, para a socialização na escola, e dela, da socialização, cabe ocupar-se outra esfera.

\section{Considerações finais}

O que cabe ao educador no século XXI, em meio a crises econômicas, políticas, sociais e sanitárias, é reivindicar e atuar "fazendo escola", o que não significa construir uma instituição, dedicar-se à arquitetura ou engenharia, mas "que dê à escola algo assim como sua condição, seu caráter mais próprio, algo que não está dado, mas que é instaurado na vida escolar, na educação feita vida” (KOHAN, 2015, p. 25). Nos termos que argumentei aqui, trata-se de "fazer" skholé, ou melhor, realizar skholé, tornar real mesmo que isso signifique tornar inoperante, temporariamente, a socialização, a "introdução na sociedade", para introduzir as "novas gerações" no mundo, naquilo que é mais duradouro que a "vida" e que dota de sentido a existência. Mas não a existência em seu passado, presente e futuro. Apenas no aqui, no isso, no agora. Não se trata de um projeto no qual as crianças, jovens e adolescentes 
são instrumentos de um objetivo adulto, mas de realizar o "tempo livre", no "tempo presente" que transforma a escola em skholé, na qual todos, que "são capazes de", podem desenvolver-se como indivíduos e cidadãos, isentos de qualquer obrigação para com a sociedade (o trabalho, a economia, o consumo), a família ou a política (MASSCHELEIN; SIMONS, 2013, p. 97).

Por isso, a skholé rompe com a instrumentalidade inerente às avaliações do homo faber e com projetos que domam a escola a partir de fora. Inspiração latino-americana, Simón Rodríguez serviu como um dos fundamentos para pensar a igualdade que se realiza na relação pedagógica, pois o filósofo e educador venezuelano "é um iniciador, um inspirador, um apostador. O que interessa está no que acontece, no que provoca, não em um produto final” (KOHAN, 2015, p. 50). Isso caracteriza as experiências de Rodríguez e nos serve de modelo para (re)pensar a escola e a educação para além da "socialização", dos processos de "introdução na sociedade". A escola, como argumentei, é um fenômeno do mundo, introduz as "novas gerações" no mundo, e tal introdução acontece com a ação e o discurso, no qual o mundo, transformado em "matérias" na escola, é objeto que indaga, confronta e exige respostas, posicionamentos, aparições. Por isso, "introduzir no mundo" é uma prática destituída de seu caráter instrumental: não é "fazer a introdução", mas "realizar", tornar real, possível, e isso acontece quando os professores apresentam o mundo às crianças e dizem: "isso é o nosso mundo" (ARENDT, 2007, p. 239).

Para pensar a skholé, é preciso desabituar-se, assumir a perspectiva do estrangeiro, do estranho, do outsider, para compreender distintamente e desnaturalizar relações e práticas que não permitem a crianças, adolescentes e jovens aparecerem como singulares ou tornarem-se o quem são (KOHAN, 2015, p. 34). Por isso, a "socialização", como "introdução na sociedade" não pode fazer parte da escola - ao menos, não como a atividade principal -, porque, como argumentei, ela desescolari$z a$ a escola, inviabiliza a skholé.

Esses argumentos não conduzem, necessariamente, à exclusão da socialização, pois todos necessitamos, também, comportar-nos, atuar conforme regras, estatutos, ordenamentos e leis, mas isso não deve ser um empecilho à ação, ao pensamento, à imaginação e à inovação, tomando como condição as necessidades pelas quais nos unimos em sociedade e a liberdade em associações. Para Rodríguez (2016, p. 137),

[...] os homens não estão em sociedade para se dizer que possuem necessidades nem para se aconselhar que busquem remediá-los... nem para se incentivar a terem paciência; mas para se consultar sobre os meios de satisfazer seus desejos, porque não satisfazê-los é padecer. 
Nessa definição, o filósofo opta pelo plural, os homens e não o homem ou a humanidade. Neste sentido, a sociedade se compreende como associação, que exige dos homens a compreensão sobre como se entender entre si e criar instituições, práticas e condutas eficazes para a satisfação das necessidades e dos desejos. Embora eles não se refiram ao "mundo", no sentido arendtiano, não se pode descartar essa esfera como importante, porque não há como voltar atrás, para os indivíduos. Importante, mas não fundamental para que uma vida individual exista como singularidade. A escola institucional transita, assim, da askholia para a skholé.

Assim, a escola também forma para a "vida". Inspirado em Simón Rodríguez, Kohan (2015, p. 80) argumenta que "é preciso formar todas as meninas e todos os meninos desta terra para o mundo, para o trabalho, para a vida", o que não significa desescolarizar a escola, a askholia usurpando a skholé: uma escola utilitária, instrumental e técnica. Cabe à escola escolar criar condições para a realização das experiências, do aprendizado pela experiência e da experiência como aprendizado. Aprender a ler e escrever não é o bastante (RODRÍGUEZ, 2016, p. 93), é importante uma educação dos sentidos e pelos sentidos - ideia que o filósofo venezuelano compartilha com Rousseau (2017, p. 53): "preparai-as, portanto, para as ameaças que um dia terão de suportar. Endurecei seu corpo às intempéries das estações, dos climas, dos elementos: à fome, à sede, ao cansaço". Pois é importante aprender a viver para poder cuidar do mundo, ser introduzido no mundo e não sucumbir à vida, à sobrevivência. Tudo isso faz parte da escola, embora nem tudo a faça escolar. "Ensinar pela metade não é ensinar" (RODRÍGUEZ, 2016, p. 101).

A educação na América integra conhecimento, pensamento, ação e a vida. São espaços (os escolares) em que é possível aparecer como singular e, a partir de Arendt (2005), isso não acontece sem os outros que garantem a realidade do indivíduo e de si mesmos em relação, no espaço entre, o "mundo" ou a "matéria" "profanada", "desprivatizada" pela escola. Eis a escola republicana: a que introduz todos no mundo, torna público e comum. Uma educação política que não é instrumento da política: "a educação é para todos ou para ninguém" (KOHAN, 2015, p. 85). Logo, ela não é um fenômeno da vida, mas do mundo.

\section{Notas}

1 Todas as traduções são de nossa autoria.

2 Nesse aspecto, em termos educacionais, Rousseau (2017, p. 99) comenta: "sabeis qual o meio mais seguro de tornar vosso filho miserável? É acostumá-lo a conseguir tudo, pois, com seus desejos crescendo continuamente pela facilidade de satisfazê-los, cedo ou tarde a impotência vos forçará a recusá-los contra a 
vossa vontade, e tal recusa inabitual causará maior tormento a vosso folho que a própria privação do que ele quer".

3 O fato de o Ministério da Economia, no Brasil de Bolsonaro, exercer preponderância, "superministério", só é possível com o advento da sociedade, na qual a economia (oikonomía) se tornou um assunto público, quando, originariamente, dizia respeito a oikos, aos assuntos domésticos, relacionados às necessidades. Quando a Economia administra a educação, negligenciando a tarefa específica que toda educação tem na civilização, há a preponderância da socialização sobre a educação, da adaptação e do conformismo sobre a ação, a introdução no mundo e a singularização.

4 Na continuidade do argumento, escreve Estefanía (2017, p. 85): "por que, apesar de tantos bem intencionados economistas neoclássicos, quase todas suas recomendações e receitas favorecem aos ricos, mais que aos pobres, aos capitalistas mais que aos assalariados, aos privilegiados antes que os despossuídos".

5 Segundo Sennett (2012, p. 17), “a falta de respeito, ainda que menos agressiva que um insulto direto, pode adotar uma forma igualmente que fere. Com a falta de respeito não se insulta a outra pessoa, mas tampouco se oferece reconhecimento; simplesmente não se a vê como um ser humano integral cuja existência importa". Contudo, o desrespeito se converte em humilhação quando vê ao outro como fracassado, preguiçoso, parasita da sociedade. É o caso da Primeira Dama do Estado de São Paulo quando falou que morar na rua é um atrativo e que os moradores de rua gostam de ficar lá. Disponível em: https:/g1.globo.com/sp/ sao-paulo/noticia/2020/07/03/bia-doria-diz-que-nao-se-deve-doar-marmitas-para-moradores-de-rua-porque-eles-gostam-de-ficar-nas-ruas-e-um-atrativo.ghtml.

6 Num artigo dos anos 1950, sobre as técnicas da ciência social e o estudo dos campos de concentração, Arendt argumenta sobre os campos de concentração como laboratórios de uma experiência de dominação total que visa eliminar a espontaneidade e transformar o homem num ser totalmente condicionando mediante a destruição da pessoa jurídica, da pessoa moral e da própria individualidade (ARENDT, 2001, p. 157).

\section{Referências}

AB'SABER, T. Crise, alucinose e mentira: 0 anticomunismo do nada brasileiro. In: ALMEIDA, R.; TONIOL, R. Conservadorismos, fascismos e fundamentalismos: análises conjunturais. Campinas, SP: Editora Unicamp, 2018. p. 117-142.

AGAMBEN, Giorgio. Profanações. São Paulo: Boitempo Editorial, 2007.

ARENDT, Hannah. A dignidade da política: ensaios e conferências. Rio de Janeiro: Relume-Dumará, 1993.

ARENDT, Hannah. A vida do espírito: o pensar, o querer, o julgar. Rio de Janeiro: Civilização Brasileira, 2009.

ARENDT, Hannah. Compreensão e política e outros ensaios. Lisboa: Relógio D’Água, 2001.

ARENDT, Hannah. Entre o passado e o futuro. 6. ed. São Paulo: Perspectiva, 2007.

ARENDT, Hannah. La condición humana. Barcelona: Paidós, 2005.

ARENDT, Hannah. Origens do totalitarismo. Antissemitismo, imperialismo, totalitarismo. São Paulo: Cia das Letras, 2012.

BALZAC, Honoré. A comédia humana. v. 8. São Paulo: Globo, 2013.

BIESTA, Gert. Para além da aprendizagem: educação democrática para um futuro humano. Belo Horizonte: Autêntica, 2013. 
BRASIL. Base Nacional Comum Curricular: educação é a base (Ensino Médio). Brasília, DF: Ministério da Educação, 2018.

BERGER, P. L.; LUCKMANN, T. A construção social da realidade: tratado de Sociologia do Conhecimento. Petrópolis: Vozes, 2004.

CAMUS, Albert. La peste. Barcelona: Editorial Sol 90, 2003.

DARDOT, Pierre; LAVAL, Christian. A nova razão do mundo: ensaio sobre a sociedade neoliberal. São Paulo: Boitempo, 2016.

DURÁN, Maximiliano; KOHAN, Walter Omar. Por que ler Simón Rodríguez? Para que traduzí-lo para o português? Por que Inventamos ou erramos? In: RODRÍGUEZ, S. Inventamos ou erramos. Belo Horizonte: Autêntica, 2016. p. 7-29.

ESTEFANÍA, Joaquin. La mentira os hará eficaces. In: FANÉS, J. I. En la era de la posverdad: 14 ensayos. Barcelona: Calambur, 2017. p. 79-89.

KALIMTZIS, Kostas. La desaparición de la skholé. La Torre del Virrey: revista de estudios culturales, n. 21, p. 1-16, 2017. Disponível em: https://dialnet.unirioja.es/descarga/articulo/6745610.pdf. Acesso: jun. 2019.

KOHAN, Walter Omar. Entre nós, em defesa de uma escola. ETD - Educação Tecnológica Digital, Campinas, v. 19, n. 4, 2017.

KOHAN, Walter Omar. $O$ mestre inventor: relatos de um viajante educador. Belo Horizonte: Autêntica, 2015.

LAVAL, Christian. A escola não é uma empresa: o neoliberalismo em ataque ao ensino público. Londrina: Editora Planta, 2004.

LOCKE, John. Alguns pensamentos sobre a educação. Lisboa: Edições 70, 2019.

LOCKE, John. Dois tratados sobre o governo. 2. ed. São Paulo: Martins Fontes, 2005.

LÓPEZ, Maximiliano Valério. A escola como suspensão. In: MARTINS, F. F. R.; NETTO, M. J. V.; KOHAN, W. O. Encontrar Escola: o ato educativo e a experiência da pesquisa em educação. Rio de Janeiro: Lamparina; FAPERJ, 2014. p. 84-91.

LARROSA, Jorge. Pedagogia profana: danças, piruetas e mascaradas. 6. ed. Belo Horizonte: Autêntica, 2017.

MARX, Karl. Sobre o suicídio. São Paulo: Boitempo, 2006.

MASSCHELEIN, Jan; SIMONS, Marteen. Em defesa da escola: uma questão pública. Belo Horizonte: Autêntica, 2013.

OLARIETA, Beatriz Fabiana. Breve história de uma instrução para perder-se na cidade. In: MARTINS, F. F. R.; NETTO, M. J. V.; KOHAN, W. O. Encontrar Escola: o ato educativo e a experiência da pesquisa em educação. Rio de Janeiro: Lamparina; FAPERJ, 2014. p. 51-65.

PENNAC, Daniel. Mal de escuela. Barcelona: Penquin Random House, 2008.

RODRÍGUEZ, Simón. Inventamos ou erramos. Belo Horizonte: Autêntica, 2016.

ROUSSEAU, Jean-Jacques. Emílio ou Da educação. São Paulo: Edipro, 2017. 
SENNETT, Richard. A cultura do novo capitalismo. São Paulo: Record, 2006.

SENNETT, Richard. El respeto: sobre la dignidad del hombre en un mundo desigual. 3. ed. Barcelona: Anagrama, 2012.

SENNETT, Richard. O declínio do homem público: as tiranias da intimidade. Rio de Janeiro: Record, 2014. 